\title{
Predicting the Extent of Wildfires Using Remotely Sensed Soil Moisture and Temperature Trends
}

\author{
David Chaparro, Mercè Vall-llossera, Maria Piles, Adriano Camps, Christoph Rüdiger, and Ramon Riera-Tatché
}

\begin{abstract}
Recent climate trends evidence a rise of temperatures and an increase in the duration and intensity of droughts which is in turn leading to the occurrence of larger wildfires, which threaten the environment as well as human lives and beings. In this context, improved wildfires prediction tools are urgently needed. In this paper, the use of remotely sensed soil moisture data as a key variable in the climate-wildfires relationship is explored. The study is centered in the fires registered in the Iberian Peninsula during the period 2010-2014. Their prior-to-occurrence surface moisturetemperature conditions were analyzed using SMOS-derived soil moisture data and ERA-Interim land surface temperature reanalysis. Results showed that moisture and temperature conditions limited the extent of wildfires, and a potential maximum burned area per moisture-temperature paired values was obtained $\left(R^{2}=0.43\right)$. The model relating fire extent with moisture-temperature preconditions was improved by including information on land cover, regions, and the month of the fire outbreak $\left(R^{2}=0.68\right)$. Model predictions had an accuracy of $83.3 \%$ with a maximum error of $\mathbf{4 0 . 5}$ ha. Results were majorly coherent with wildfires behavior in the Iberian Peninsula and reflected the duality between Euro-Siberian and Mediterranean regions in terms of expected burned area. The proposed model has a promising potential for the enhancement of fire prevention services.
\end{abstract}

Index Terms-Wildfires, remote sensing, soil moisture measurements, land surface temperature, and burned area.

\section{INTRODUCTION}

Wildfires are an important issue due to their inherent environmental, economic and social impacts. Some ecosystems need naturally occurring fires to maintain their dynamics. However, damages caused by these fires are mostly vast in economic and environmental terms [1]. Also, most wildfires happen in patchy landscapes where boundaries among forests, agricultural and urban areas might be vague, representing a risk for human lives and beings. In particular, the expansion of wildland urban interface areas in some countries such as the United States ([2] and [3]) rises these risks. Also, the systematic suppression of fires increases fuel accumulation and brings to dangerous situations (this is known as the fire suppression paradigm; [4]). Furthermore, several human-derived fac- tors (e.g., roads, population density, land use changes, etc.) are determinant in fire ignition [3], [5], [6]. Hence, anthropogenic activities directly or indirectly play a major role in forest fire dynamics, with $95 \%$ of wildfires in the Mediterranean region being caused by humans [1], [7]-[9].

Besides human activity and fire suppression, biogeophysical factors (mainly vegetation, topography and weather) strongly condition fire patterns and the extension of burned area [6], [8], [10]-[12]. Vegetation abundance, structure, and distribution are determinant in wildfire ignition and spread [13]. Topography influences vegetation distribution, local climate, and fuel moisture, and produces supplemental wind effects in steep slopes [13], [14]. Weather, in turn, plays a key role on the ignition conditions as it determines the fire environment [5]. In particular, wind is the most important driver of fire propagation as it desiccates fuels and drives fire fronts [13]. The coexistence of strong winds with high temperatures and dry soil conditions favors the occurrence and spread of large wildfires at regional scales [15], [16], and can lead to vast burned extensions even in a few days (e.g., [16]). In this context, a thoroughly study of moisture and temperature influence on wildfires is paramount.

Present changing climate conditions and, more particularly, the increase on temperatures and on the duration and intensity of droughts, are leading to larger and more frequent forest fires, as a result of facilitated drying and combustion of vegetation fuels [17]. This situation is critical in regions such as the Mediterranean basin, where temperatures are expected to increase by 3-5 ${ }^{\circ} \mathrm{C}$ during the current century [18]. Moreover, the climate in regions such as the Iberian Peninsula favors wildfire occurrences and propagation mainly during summer, when the high number of fire outbreaks difficult fire extinction tasks, especially in Portugal. This factor, combined with low rainfall and high temperatures, favors the occurrence of large forest fires particularly in the driest years (e.g., fires up to 32400 ha in 2012). Moisture and temperature have a major influence on the burning risk as they affect the water content of litter which, in terms of forest fire ignition and propagation capacity, is 
the most dangerous fuel [19]. Thus, the study of moisture and temperature conditions prior to fire occurrence is important to further our understanding of the weather-fire relationship. This can help improving forest fire risk assessment, which is crucial both for prevention and for fast reaction in case of wildfire.

Concerning to the Iberian Peninsula, the Fine Fuel Moisture Code (FFMC) is one of the most important variables in forest fire prediction in northwestern Spain [5]. The FFMC is strongly related to soil moisture. As explained in [19], soil moisture is a limiting factor in wildland fire propagation in the region, as it determines fuels' flammability. In that regard, drought was one of the influencing factors in the 2003 heat wave, which led to record-breaking wildfires in Portugal in that summer [16], [20]. Most widely-used fire risk indices employ information on soil moisture and litter water content. The previously mentioned FFMC, or the United States National Fire Danger Rating System [21], [22], are good examples of indices using indirect information of litter's moisture. However, these indices are entirely based on in situ meteorological data, and require a high density of meteorological stations to provide good coverage. Moreover, the moisture information used is not directly obtained in most stations, but inferred from other variables (e.g., temperature, precipitation or relative humidity). Alternatively, a quantitative estimation of soil moisture is provided by recently launched satellite missions dedicated to measuring the Earth's surface soil moisture: the ESA's Soil Moisture and Ocean Salinity (SMOS; [23]) and the NASA's Soil Moisture Active Passive (SMAP; [24]). Earth observing satellites provide frequent data cover and accurate information that could help forest fire prevention activities. In [25], a soil moisture dataset derived from Earth Observation Satellites (ERS-1/2) was used to study prefire conditions in Central Siberia. The authors concluded that wet soil surface limited the extent of burned area and that $80 \%$ of wildfires occurred under dry soil conditions in summer. Also, soil moisture data from the Advanced Microwave Scanning Radiometer-Earth Observing System (AMSR-E) was used in [26], identifying surface moisture as an important factor determining the evolution of extreme wildfire events in the region of Lake Baikal (Siberia). However, these studies were conducted in very different conditions from those found in the Iberian Peninsula. Also, the measurements from ERS-1/2 and AMSRE were limited by low penetration through vegetation and by high exposition to RFI [23].

The ESA's SMOS mission, launched in 2009, is the first space mission specifically launched to measuring soil moisture. SMOS operates at the L-band protected frequency and provides global maps of surface soil moisture (top $5 \mathrm{~cm}$ ) every 3 days with a spatial resolution of $\sim 40 \mathrm{~km}$, and a target accuracy of $0.04 \mathrm{~m}^{3} \cdot \mathrm{m}^{-}$ 3

[27]. Moreover, vegetation at this frequency is transparent till $5 \mathrm{~kg} \cdot \mathrm{m}^{-2}$, which permits measuring soil moisture in approximately the $65 \%$ of emerged lands. The SMOS resolution serves global climate-related applications but is too coarse for regional and practical applications which require higher spatial resolutions on the order of $1 \mathrm{~km}$ or less. In this regard, a SMOS-derived soil moisture product at fine scales has been derived by combination with soil surface temperature and NDVI, using the downscaling algorithm in [28]. These maps are available at the Barcelona Expert Centre (BEC) web service [29].
BEC fine-scale SMOS data and ERA-Interim reanalysis of land surface temperature were used in [30] to conclude that dry and hot soil conditions preceded big wildland fires occurrence whereas smaller fires tended to present wetter and colder conditions. From this analysis, forest fire risk thresholds dependent on moisture and temperature were obtained. These were later used to produce experimental fire risk maps that, since July 2015, are available in near real time at BEC facilities [29]. These maps have been used by the Barcelona Provincial Council's forest fire prevention service in their early warning system, to provide information on extremely dry soil and vegetation conditions posing a risk of wildfire. This study leverages from this work, and focuses on three main aspects: 1) understanding the relationship between soil moisture-temperature combined information and wildfire burned area in the Iberian Peninsula and Balearic Islands, 2) determining the usefulness of SMOS observations in assessing wildland fire potential burned area, and 3) developing a model relating surface moisture-temperature conditions to the extent of wildfires. Hereafter, the potential extent of a wildfire is defined as the maximum spread at given moisture-temperature conditions. To achieve these three objectives, the relationship between soil moisture, land surface temperature and burned area over the study region was analyzed for the period 2010 2014. A model is proposed to estimate the potential extension of forest fires as a function of soil moisture, surface temperature, and complementary data of land cover, regions, and the month of the fire outbreak.

\section{MATERIALS AND METHODS}

\section{A. Data}

The present study was carried out on the Iberian Peninsula and the Balearic Islands during the period 2010-2014. The set of variables included fire burned area, soil moisture and land surface temperature conditions prior to fire occurrence, land cover, regions, and the month of the fire outbreak.

SMOS-derived soil moisture data at $1 \mathrm{~km}$ resolution, for ascending passes ( $~ 6$ A.M. local time) was used [28], [29]. Daily land surface temperature (LST) at $0.125^{\circ}$ was obtained from ERA-Interim models of the European Centre for MediumRange Weather Forecasts (ECMWF; [31]). It is a reanalysis dataset for 12 A.M. (local time). It was interpolated to the soil moisture $1 \mathrm{~km}$ grid using the nearest neighbor method.

Land cover data from CORINE Land Cover Map [32] at $250 \mathrm{~m}$ resolution was used to classify the fires depending on the vegetation burned. CORINE provides 44 categories of land cover classified in 5 groups: artificial surfaces, agricultural areas, forest and semi-natural areas, wetlands, and water bodies. Also, it was needed to classify fires in function of their geographic region and its biogeophysical and climatic characteristics. The 53 ecoregions defined by the Spanish Forest Service were useful to this proposal, as it has been previously shown in [5]. In Portugal, the geographical division was based on the map of phytogeographic regions included in the environmental atlas of Portugal [33].

Finally, a forest fires dataset containing fires affecting more than 10 ha for the period 2006-2014 was provided by the European Forest Fires Information System (EFFIS, [34]). The 

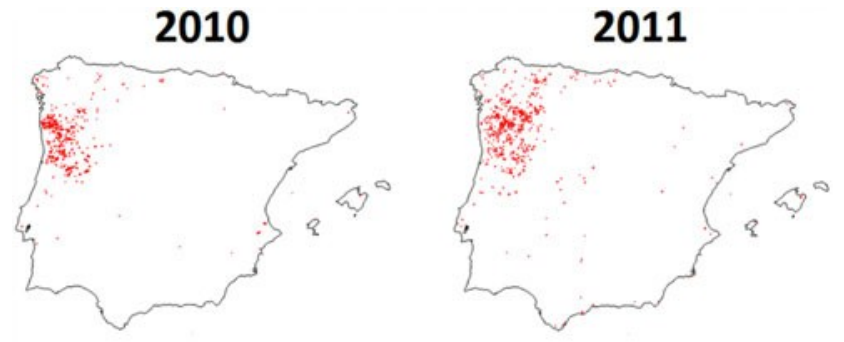

2012
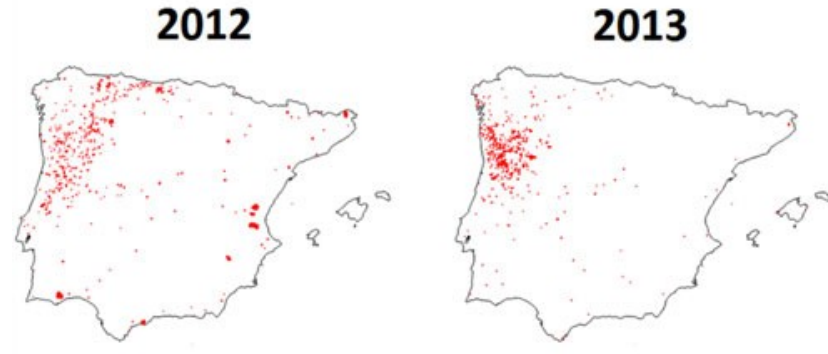

2014
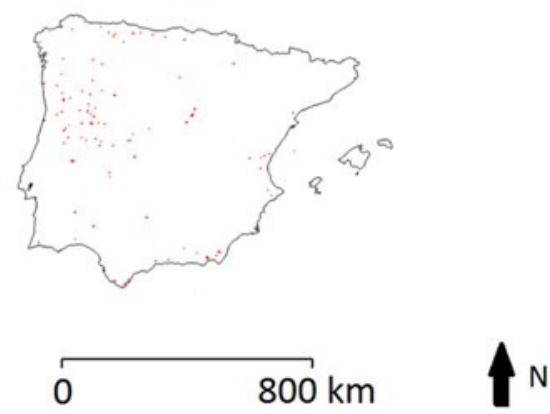

Fig. 1. Wildland fires in the Iberian Peninsula and Balearic Islands (from EFFIS database) occurred in the period 2010-2014.

TABLE I

SAMPLE OF FIRES

\begin{tabular}{lc}
\hline \hline Burned area & Number of fires \\
\hline $10-100$ ha & 968 \\
$100-1000$ ha & 971 \\
$1000-10000$ ha & 131 \\
$>10000$ ha & 6 \\
\hline Total & 2076 \\
\hline \hline
\end{tabular}

Number of fires classified by the size of burned area.

provided GIS layout included wildfires’ perimeters, coordinates and date of occurrence, among other information. Data for the period 2006-2009 was used as complementary information in the characterization of forest fires (see Section 3-A). The finally studied dataset (2010-2014) contained 2076 wildland fires larger than 10 ha, which are represented in the Iberian Peninsula in Fig. 1. Approximately the $90 \%$ of those fires were smaller than 1000 ha, while the remaining $10 \%$ was larger. Only six fires were larger than 10000 ha (see Table I).

\section{B. Study Area}

The study area included the Iberian Peninsula and the Balearic Islands $\left(-9.9^{\circ} \mathrm{W}-4.4^{\circ} \mathrm{E} ; 43.9^{\circ} \mathrm{N}-35.9^{\circ} \mathrm{N}\right)$ covering

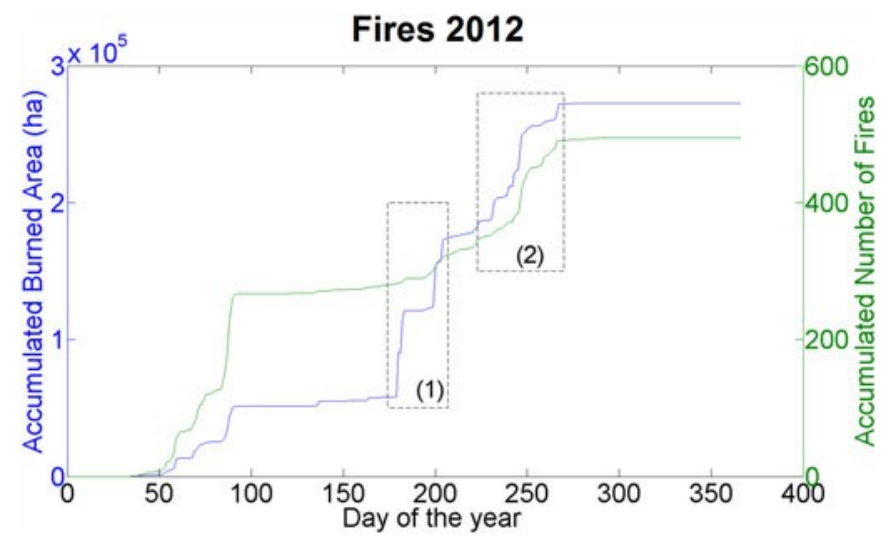

Fig. 2. Accumulated number of wildfires and accumulated burned area during 2012. Two patterns are observed: (1) Few, but big wildland fires (mean area $=2872 \mathrm{ha}$ ), which correspond to those occurred in few days on the Mediterranean region, and (2), numerous smaller forest fires (mean area $=608 \mathrm{ha}$ ) occurred on the northern Iberian Peninsula and Portugal.

approximately $600000 \mathrm{~km}^{2}$. It contains three main climatic regions: 1) the Mediterranean region, which suffers hot and dry summers, but mild winters; 2) the central plateau, which has a continental climate with hot summers and cold winters; and 3) the Atlantic regions (northern Iberian Peninsula and west of Portugal) which have smaller seasonal contrast of temperatures and precipitations, with fresh summers and mild winters.

The Iberian Peninsula is a high fire-risk region [5], [35], [36], where wildland fires cause important damage and economic loss. During the period 2010-2014, a total of 763568 ha burned (only considering fires $>10$ ha registered in EFFIS). However, this number broadly varied among different years. The geographical distribution of wildfires and their area are shown in Fig. 1. In 2010, 2011 and 2013, the burned area ranged between 125000 and 191000 ha. Rarely, only 33500 ha were burned in 2014, which was a cold and wet year. In contrast, in 2012 temperatures were generally $2{ }^{\circ} \mathrm{C}$ above the mean and precipitations 15\% below it (reference period 1971-2000; [37]). Fig. 2 shows the evolution of burned area and number of forest fires during 2012, when the accumulated burned area almost doubled that from other years (272 670 ha). The drought situation during that year favored the occurrence of big forest fires (up to $32500 \mathrm{ha}$ ) especially in the Mediterranean region (see Fig. 1). In this region, the availability of fuel is usually a limiting factor to fire propagation. However, after long periods of low fire activity, this situation changes and enough combustible is finally accumulated. Then, low humidity and high temperatures pose a high risk of large fires (see [38]). In contrast, forested landscape prevails in the northern regions, where typically numerous but smaller wildfires burn (see Fig. 1) due to the availability of a lot of fuel under more humid conditions. This pattern is char- acterized by an increase in burned area due to high number of relatively small fires (see Fig. 3; e.g., 2010 and 2013), rather than to few but big fire occurrences like in the Mediterranean region. However, anomalous dry and hot conditions also led to large for- est fires in northern Spain and northern Portugal during February and March 2012 (see Fig. 2; fire extensions up to 2000 ha) and during October 2011 (see Fig. 3; burned area up to 2700 ha). Fi 


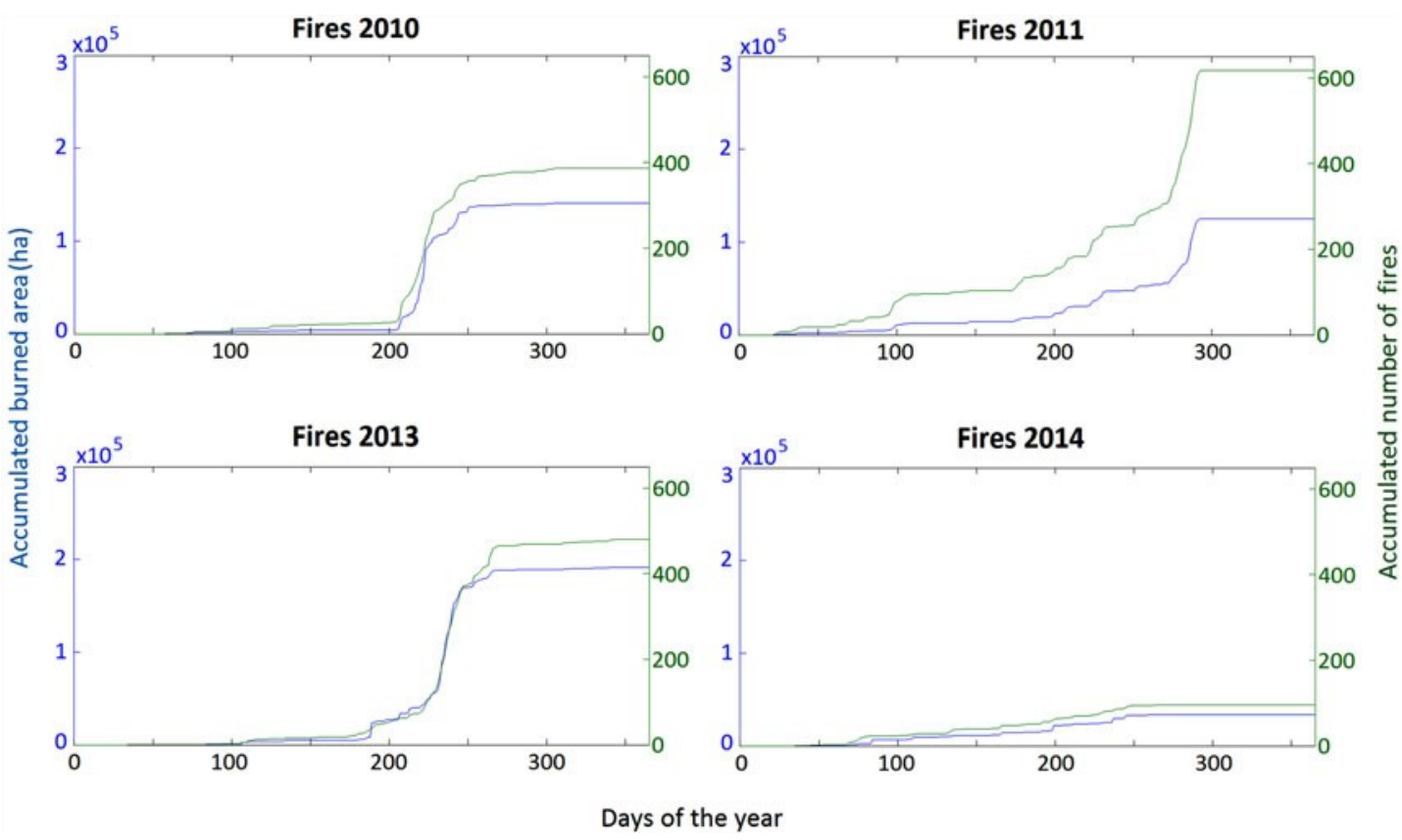

Fig. 3. Accumulated number of fires and accumulated burned area in 2010, 2011, 2013, and 2014.

nally, note that fires $<10$ ha (not studied here) are quantitatively important (e.g., in the period 1984-2004, 25\% of fires larger than 5 ha in Portugal did not exceed a size of 10 ha [40]).

\section{Data Preparation}

In order to obtain one single datum per variable and burn episode, the GIS layout containing forest fire perimeters was clipped to soil moisture, land surface temperature, land cover and regions layers. The median soil moisture and land surface temperature of all pixels within each fire were calculated and assigned to each episode. A $3 \%$ of fires did not account with moisture and/or temperature data for the day of occurrence to three days backwards, and were therefore eliminated from the database. This resulted in a final database containing 2013 forest fires.

One single category of land cover was assigned to each wildfire, corresponding to the modal cover within the fire-affected area. Agricultural lands were considered as a single cover category.

The region was also assigned to each forest fire. In the few cases in which a fire occurred across more than one region, the region assigned to the episode was the one containing the larger burned area. Regions were grouped as shown in Fig. 4 in order to simplify the study. Due to different climates and forest fire patterns, ecoregions in the north of Spain (28.9\% of fires) and Mediterranean regions (4.8\% of fires) were considered separately. A third group was formed with the central Spanish ecoregions (5.7\%) located in inland Peninsula and, in most cases, within the continental climate of the central plateau. In Portugal, the general phytogeographic classification assembles 24 regions in three general groups (North, Centre and South; [33]). However, in order to consider different biogeographic characteristics within the country [40], [41], here five regions

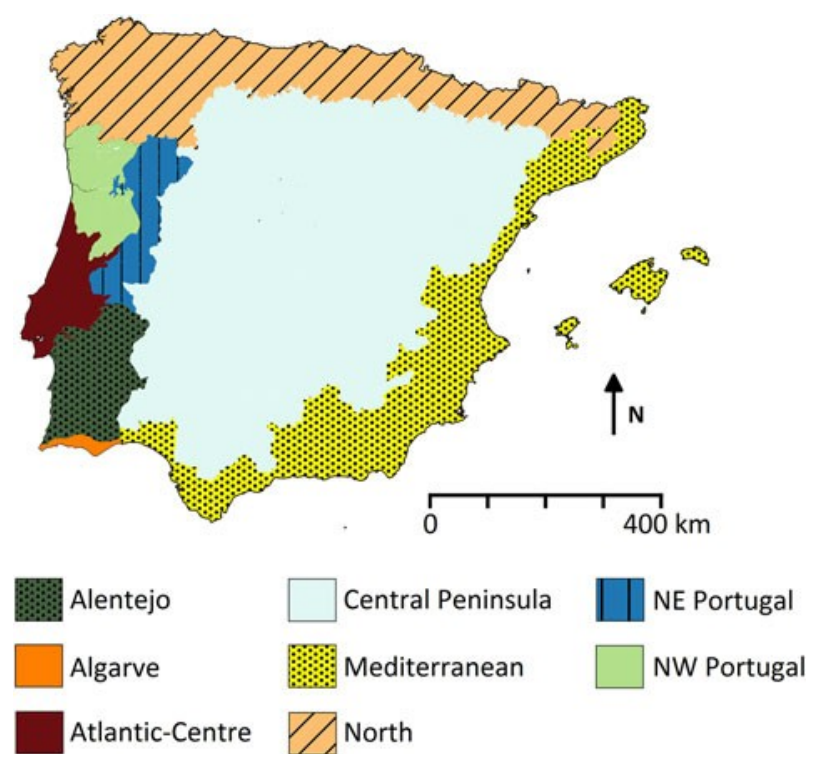

Fig. 4. Regions defined in the study.

were finally delimited: northwestern Portugal (43.2\% of fires), northeastern Portugal (13.6\%), Atlantic-Centre (2.8\%), Alentejo (0.8\%) and Algarve (0.2\%).

\section{Linear Model to Predict Potential Extension OF WILDFIRES}

\section{A. Characterization of Soil Moisture-Land Surface Temperature Prefire Conditions}

Firstly, pre-fire conditions were compared with unburned areas. For this purpose, a second database was built including soil moisture and land surface temperature data in more than 50000 unburned cells per year. These cells were chosen ran- 


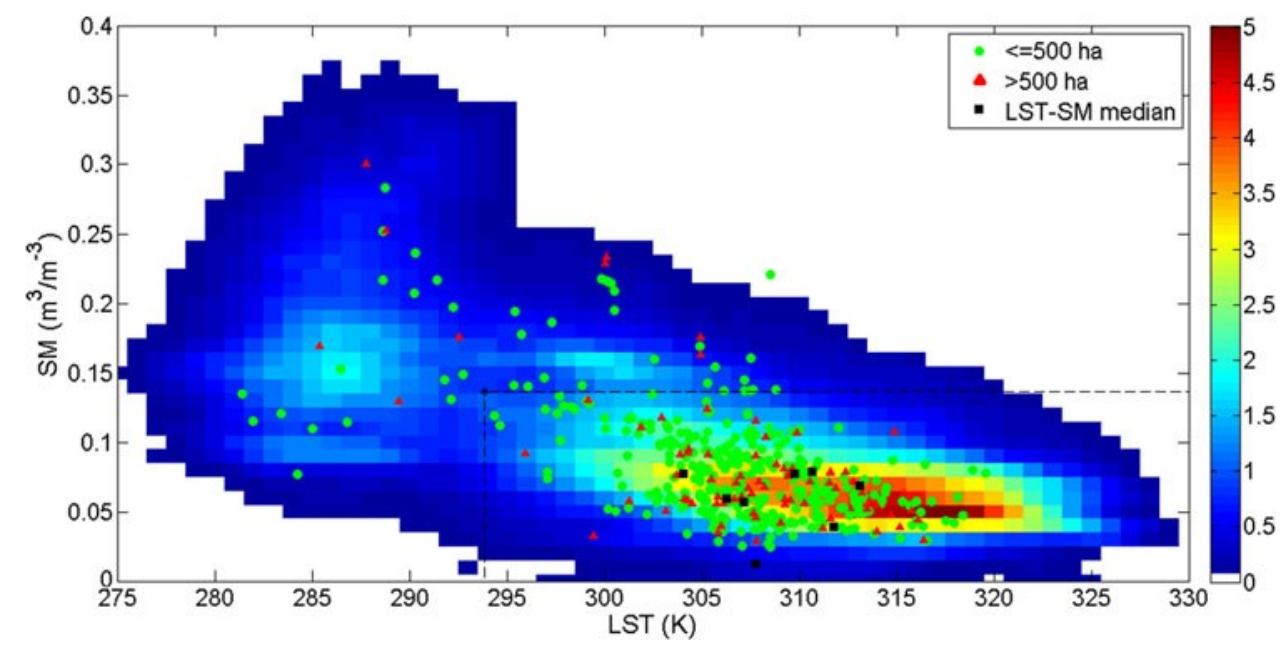

Fig. 5. Soil moisture-land surface temperature conditions comparison between burned and unburned areas during 2013. Green points, red triangles and black squares correspond to wildfires $<500$ ha, 500-3000 ha and >3000 ha, respectively. They are plotted as a function of moisture and temperature conditions prior to forest fire occurrences. Black dashed lines show the median soil moisture and land surface temperature during 2013 in unburned pixels. The distribution for both variables in not burned areas during 2013 is shown as \%o of pixels and days presenting each pair of moisture-temperature values. White represents < $0.1 \%$.

domly after excluding 1) pixels without inflammable soil uses (based on CORINE Land Cover Map), and 2) all the burned cells from 2006 to the study year. The latter criterion was used as previously burned cells are less probably affected by wildland fires until vegetation recovers some years later. Once the databases were prepared, moisture and temperature conditions for both burned and unburned cells were plotted. Fig. 5 shows results for year 2013 as an example. Note that fires were classified in three groups ( $<500,500-3000$, and $>3000$ ha) in order to simplify interpretation. It can be seen that, although dry and warm conditions are usual in the Iberian Peninsula, the distribution of burned cells showed narrower ranges within the two studied variables in comparison to unburned pixels. In particular, density areas with $>3 \%$ of the unburned points are characterized by moisture under $0.10 \mathrm{~m}^{3} \cdot \mathrm{m}^{-3}$, and by temperature above $300 \mathrm{~K}$.

Most burned areas were in drier and hotter conditions than the annual median for both variables in the unburned zones. The percentage of pixels with drier and hotter soils than the median was $77.3 \%$ for wildfires $<500$ ha, $88.5 \%$ for wildfires between 500 and 3000 ha, and 100\% for wildfires >3000 ha. Consequently, low soil moisture and high land surface temperatures led to the largest forest fires.

\section{B. Development of the Predictive Model}

Soil moisture and temperature were plotted against burned area, which was logarithmically transformed (decimal logarithm). Fig. 6 shows that the distribution results in triangleshaped plots where both moisture and temperature limit the fire extent. A regression was fit along the imaginary hypotenuse of each triangle to express the maximum burned area as a function of soil moisture and land surface temperature. As there was no strong redundancy between moisture and temperature ( $r=-0.54$; Pearson correlation coefficient), the two variables

were combined in a single model. Model fitting was carried out randomly sampling a $70 \%$ of the dataset, while the remaining $30 \%$ was used later for validation.

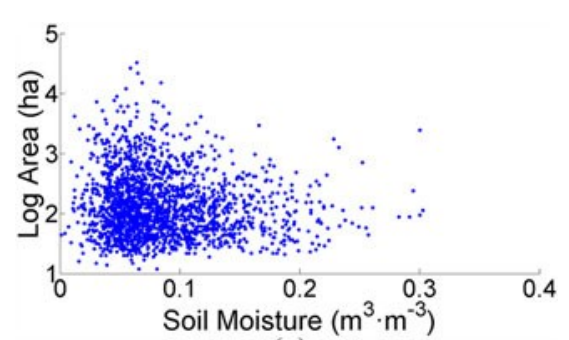

(a)

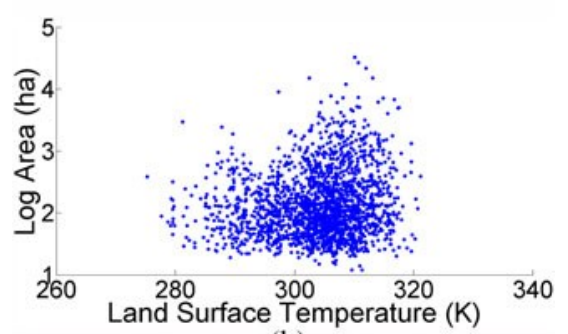

(b)

Fig. 6. (a) Decimal logarithm of the burned area for wildfires between 2010 and 2014, plotted as a function of soil moisture. (b) Decimal logarithm of the area for wildfires between 2010 and 2014 plotted as a function of land surface temperature.

In order to perform the regression analysis, it was necessary to define bins for soil moisture and land surface temperature, and assign a value of maximum burned area to each bin. This approximation was founded on other studies based on triangular-shaped relationships between environmental variables [42], [43]. Here, in order to increase the sample, it was decided to include in the regression all wildfires larger than the 90th percentile of burned area for each bin.

To study the impact of the bin width on the results, several binning possibilities (from $\left[0.005 \mathrm{~m}^{3} \cdot \mathrm{m}^{-3}-0.5 \mathrm{~K}\right]$ to $\left.\left[0.02 \mathrm{~m}^{3} \cdot \mathrm{m}^{-3}-2 \mathrm{~K}\right]\right)$ were explored for the following linear regression:

$$
\text { LogArea } \approx a \cdot S M+b \cdot \mathrm{LST} \text {. }
$$


where LogArea corresponds to the decimal logarithm of burned area, SM states for soil moisture, and LST for land surface temperature. Their corresponding coefficients are $a$ and $b$. Higher order models did not improve the fitting (results not shown).

Forest fires with moisture and temperature at the extremes of the variables' ranges (beyond percentiles 5 and 95) were eliminated, as the sample of fires is reduced in that conditions and do not show a representative maximum according to the moisture-temperature data. The best regression in terms of $R^{2}$ was obtained for the $\left[0.01 \mathrm{~m}^{3} \cdot \mathrm{m}^{-3}-2 \mathrm{~K}\right]$ binning $\left(\mathrm{R}^{2}=0.43\right)$. The sample contained 183 wildfires and soil moisture and land surface temperature values ranged from 0.035 to $0.170 \mathrm{~m}^{3} \cdot \mathrm{m}^{-3}$ and from 289.8 to $314.3 \mathrm{~K}$, respectively.

Using this result as a basis, a linear model predicting the potential extent of forest fires was developed including land cover, the month when the wildfire occurred, and the region of burning as additional variables. The interactions soil moisture $\times$ month, soil moisture $\times$ region, and temperature $\times$ region were also included in the model as their effects were significant. The interaction soil moisture $x$ land cover and the interactions combining land surface temperature with month and land cover were not significant and were therefore excluded. Eight land cover categories were considered: broadleaved forests, coniferous forests, mixed forests, heathlands and moors, sclerophyllous vegetation, natural grasslands, woodland-shrub transitions and sparse vegetation areas. Concerning to months, the analyzed forest fires occurred in February, March, April, June, July, August, September, and October. Wildland fires occurring in other months, as well as those burning in agricultural areas did not achieve a minimum sample ( $n \geq 5$ ) and were excluded. The same happened for the Portuguese regions of Alentejo, Algarve, and CentralAtlantic regions, where the amount of data was not sufficient. As a result, the model only considered the northernmost regions of Portugal. The final sample was of 168 forest fires (see Table II). The resulting model can be expressed as

$$
\text { LogArea } \sim c+M+\mathrm{LC}+R+\mathrm{a}_{(M, R)} \cdot \mathrm{SM}+b_{(R)} \cdot \mathrm{LST}
$$

where $c$ is the intercept corresponding to the logarithm of the potential burned area in the northern Peninsula, on February, for a broadleaved forest land cover. $M$, LC and $R$ correspond to the additive terms of month, land cover, and region, respectively. The term $a_{(M, R)}$ is the slope for soil moisture (SM), which depends on the month and the region, and $b_{(R)}$ is the slope for land surface temperature (LST), which depends on the region. The analysis of the variance of the model is reported in Table III. The coefficients and terms of the model are reported in Table IV.

As some months were excluded in the proposed model, it was necessary to provide a complementary equation without the variable month, which could be validated and later used in operational applications during January, May, November and December. This model contains the same terms and structure detailed in (2) with the only difference that months were eliminated

$$
\text { LogArea } \sim c+\mathrm{LC}+R+\mathrm{a}_{(R)} \cdot \mathrm{SM}+b_{(R)} \cdot \mathrm{LST} \text {. }
$$

TABLE II

SAMPLE OF THE MODEL

\begin{tabular}{llc}
\hline \hline & Variables & Sample \\
\hline Soil Moisture & & 168 \\
\hline Land Surface Temperature & 168 \\
\hline Month & February & 7 \\
& March & 33 \\
& April & 7 \\
& June & 7 \\
& July & 10 \\
& August & 58 \\
& September & 23 \\
& October & 23 \\
\hline Land cover & Broadleaved forests & 10 \\
& Coniferous forests & 6 \\
& Mixed forests & 8 \\
& Natural grasslands & 26 \\
& Heathlands and moors & 33 \\
& Sclerophyllous vegetation & 16 \\
& Wood-shrubland transition & 51 \\
& Sparse vegetation & 18 \\
\hline Region & Central Peninsula & 6 \\
& Mediterranean & 12 \\
& North & 50 \\
& Northeastern Portugal & 25 \\
& Northwestern Portugal & 75 \\
\hline
\end{tabular}

Number of wildfires studied in the proposed model for each variable and interaction.

TABLE III

ANALYSIS OF THE VARIANCE

\begin{tabular}{lccccc}
\hline \hline Variable & Sum. Sq. & Df & $F$ value & p-Value & Sig. \\
\hline Soil Moisture & 5.83 & 1 & 53.87 & $<0.001$ & $* *$ \\
Land Surface Temperature & 0.47 & 1 & 4.36 & 0.04 & $*$ \\
Month & 1.02 & 7 & 1.35 & 0.23 & \\
Region & 1.29 & 4 & 2.97 & 0.02 & $*$ \\
Land Cover & 2.71 & 7 & 3.58 & $<0.001$ & $*$ \\
Soil Moisture x Month & 3.49 & 7 & 4.61 & $<0.001$ & $* *$ \\
Soil Moisture x Region & 4.21 & 4 & 9.72 & $<0.001$ & $* *$ \\
Land Surface Temperature x Region & 7.62 & 4 & 17.60 & $<0.001$ & $* *$ \\
Residuals & 14.29 & 132 & & & \\
${\text { Multiple } R^{2}=0.75 \text {, Adjusted } R^{2}=0.68}^{2}$ & & & & &
\end{tabular}

Analysis of the Variance for the proposed model of potential extension of wildfires as a function of soil moisture, land surface temperature, month, region, and land cover. Significance (Sig.) is given as $p<0.1(),. p<0.05(*), p<0.01(* *)$ and $p<0.001(* * *)$ ).

Similarly, agricultural lands were not considered in the main model, so a complementary equation excluding the land cover variable is needed for these areas

$$
\text { LogArea } \sim c+M+R+a_{(M, R)} \cdot \mathrm{SM}+b_{(R)} \cdot \mathrm{LST} \text {. }
$$

\section{RESULTS}

The model defined in (2) explained $68 \%$ of the variance of the potential extension of wildfires (see Table 3). In particular, $33.1 \%$ of the variance was explained by soil moisture, $19.8 \%$ by land surface temperature, $2.5 \%$ by the month when the forest fire occurred, $6.6 \%$ by the majorly affected land cover, and $3.1 \%$ by the region where the fire took place (see Table 3 ). The complementary model excluding months (3) explained $62 \%$ of the variance, while the model without the land cover variable showed in (4) explained 64\%. 
TABLE IV

SUMMARY OF THE MODEL

\begin{tabular}{|c|c|c|c|c|c|c|}
\hline (Intercept) February, North, ForB & -15.32 & \pm & 3.66 & -4.19 & $<0.01$ & $* * *$ \\
\hline Soil Moisture & -4.03 & \pm & 4.71 & -0.86 & 0.39 & \\
\hline Land Surface Temperature & 0.06 & \pm & 0.01 & 5.07 & $<0.01$ & $* * *$ \\
\hline March & -0.19 & \pm & 0.64 & -0.29 & 0.77 & \\
\hline April & -0.51 & \pm & 0.64 & -0.81 & 0.42 & \\
\hline June & 2.39 & \pm & 0.78 & 3.08 & $<0.01$ & ** \\
\hline July & 0.86 & \pm & 0.66 & 1.31 & 0.19 & \\
\hline August & -0.06 & \pm & 0.55 & -0.10 & 0.92 & \\
\hline September & -0.63 & \pm & 0.56 & -1.11 & 0.27 & \\
\hline October & 0.08 & \pm & 0.60 & 0.14 & 0.89 & \\
\hline Central Peninsula & 34.39 & \pm & 35.06 & 0.98 & 0.33 & \\
\hline Mediterranean & 67.09 & \pm & 9.04 & 7.42 & $<0.01$ & $* * *$ \\
\hline NE Portugal & 3.11 & \pm & 5.58 & 0.56 & 0.58 & \\
\hline NW Portugal & 19.44 & \pm & 4.31 & 4.51 & $<0.01$ & $* * *$ \\
\hline Coniferous forest & 0.49 & \pm & 0.18 & 2.74 & 0.01 & $* *$ \\
\hline Mixed forest & 0.15 & \pm & 0.17 & 0.87 & 0.38 & \\
\hline Natural grasslands & -0.04 & \pm & 0.14 & -0.31 & 0.76 & \\
\hline Heathlands-moors & -0.05 & \pm & 0.13 & 0.39 & 0.70 & \\
\hline Sclerophyllous vegetation & 0.11 & \pm & 0.17 & 0.68 & 0.50 & \\
\hline Woodland-shrub & -0.04 & \pm & 0.12 & -0.32 & 0.75 & \\
\hline Sparse vegetation & 0.28 & \pm & 0.14 & 1.99 & 0.05 & $*$ \\
\hline Soil Moisture x March & 1.04 & \pm & 5.07 & 0.20 & 0.84 & \\
\hline Soil Moisture x April & 3.09 & \pm & 5.18 & 0.60 & 0.55 & \\
\hline Soil Moisture x June & -18.09 & \pm & 6.31 & -2.87 & $<0.01$ & ** \\
\hline Soil Moisture x July & -8.39 & \pm & 5.60 & -1.50 & 0.14 & \\
\hline Soil Moisture x August & 2.23 & \pm & 4.62 & 0.48 & 0.63 & \\
\hline Soil Moisture x September & 6.41 & \pm & 4.69 & 1.37 & 0.17 & \\
\hline Soil Moisture x October & -2.19 & \pm & 5.28 & -0.41 & 0.68 & \\
\hline Soil Moisture x Central Peninsula & -15.84 & \pm & 10.59 & -1.50 & 0.14 & \\
\hline Soil Moisture x Mediterranean & -21.67 & \pm & 4.28 & -5.06 & $<0.01$ & **** \\
\hline Soil Moisture x NE Portugal & 4.64 & \pm & 3.30 & 1.40 & 0.16 & \\
\hline Soil Moisture x NW Portugal & -6.77 & \pm & 2.40 & -2.82 & 0.01 & $* *$ \\
\hline LST x Central Peninsula & -0.11 & \pm & 0.11 & -0.97 & 0.33 & \\
\hline LST x Mediterranean & -0.21 & \pm & 0.03 & -7.33 & $<0.01$ & $* * *$ \\
\hline LST x NE Portugal & -0.01 & \pm & 0.02 & -0.65 & 0.52 & \\
\hline LST x NW Portugal & -0.06 & \pm & 0.01 & -4.51 & $<0.01$ & **** \\
\hline
\end{tabular}

Summary of the model proposed in (2) of potential extension of wildfires as a function of soil moisture, land surface temperature, month, region, and land cover. The significance of all effects is referred to the northern Iberian Peninsula (North), in broadleaved forests (ForB), on February (intercept). Estimates in shaded areas are additive to the intercept. Estimates in white areas correspond to slopes (Soil Moisture and Land Surface Temperature) or modify Soil Moisture and Land Surface Temperature (LST) slopes additively (interactions). Significance is given as $\mathrm{p}<0.1$ (.), $\mathrm{p}<0.05\left(^{*}\right), \mathrm{p}<0.01\left(^{* *}\right)$ and $\mathrm{p}<0.001(* * *)$. Further insight in similar models can be found in [44] if the reader is not familiar with this model output.

Summary of the model proposed in (2) of potential extension of wildfires as a function of soil moisture, land surface temperature, month, region, and land cover. The significance of all effects is referred to the northern Iberian Peninsula (North), in broadleaved forests (ForB), on February (intercept). Estimates in shaded areas are additive to the intercept. Estimates in white areas correspond to slopes (Soil Moisture and Land Surface Temperature) or modify Soil Moisture and Land Surface Temperature (LST) slopes additively (interactions).

Significance is given as $p<0.1($ ) $, p<0.05(*), p<0.01(* *)$ and $p<0.001$ (* **).

Further insight in similar models can be found in [44] if the reader is not familiar with this model output.

Figs. 7 and 8 show the predicted effect of soil moisture on the potential burned area. Dry soils led to an increased risk of forest fire propagation in most regions and months (see Figs. 7 and 8, respectively), with the exceptions of northwestern Portugal and the month of September. High temperatures facilitated wildfire spread in the north of the Iberian Peninsula and in northwestern Portugal (see Fig. 9). Unexpectedly, the effect was opposed in the Mediterranean region (see Fig. 9). No significant effect of temperature was found in the other regions.

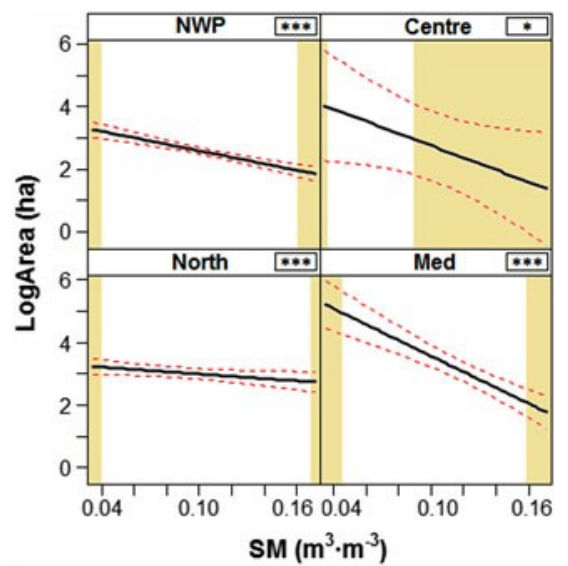

Fig. 7. Modeled effect of soil moisture on the potential extension of wildfires for each of the significant interactions between soil moisture and regions: northwestern Portugal (NWP), central Peninsula (Centre), northern Iberian Peninsula (North), and Mediterranean (Med). Black lines show the modeled effects and dashed lines show 95\% confidence intervals. Shaded rectangles show moisture values out of the range for each region, where effects are extrapolated. Top-right boxes show the significance of the effects for a given region, as $p<0.1(),. p<0.05(*), p<0.01(* *)$ and $p<0.001(* * *)$.

The highest propagation risk was reported on summer, especially during June (see Fig. 10).

Coniferous forests were the land cover with higher potential spread, while the risk was the lowest in broadleaved forests, grasslands, heathlands and moors, and woodland-shrub transitions (see Fig. 11). The Mediterranean region showed higher risk of large wildfires than other regions (see Fig. 12).

The validation of the model proposed in (2) showed that 83.3\% of wildfires were under the predicted maximum extent. The remaining $16.7 \%$ showed a maximum error of 40.5 ha. The validation for the complementary model defined in (3) resulted in $83.5 \%$ of accuracy and a maximum error of 44.6 ha. Using the model in (4), the accuracy was of $84.8 \%$. It is important to note that only one out of the 86 episodes exceeding the extent predicted in (4) presented a very large error (1487 ha), while the remaining fires had a maximum error of 40.8 ha.

\section{DISCUSSION}

\section{A. Soil Moisture and Land Surface Temperature Condition Wildfire Spreading}

SMOS-derived soil moisture was found to be an important explanatory variable in evaluating fire propagation, in particular the potential extent of wildfires. Results showed that wet soils strongly limited burned area in the Iberian Peninsula whereas drier soils increased the potential risk of large forest fires (see Fig. 6). This result is consistent with similar studies in other regions of the world [25]. Also, as expected, an inverse effect was found for land surface temperature, as large wildfires usually occurred in hot conditions (see Fig. 6). This study showed that soil moisture and temperature provide complementary information and that high temperatures and dry soils were necessary for the development of large wildland fires. Actually, all forest fires larger than 3000 ha occurred in drier and hotter than normal unburned conditions. 


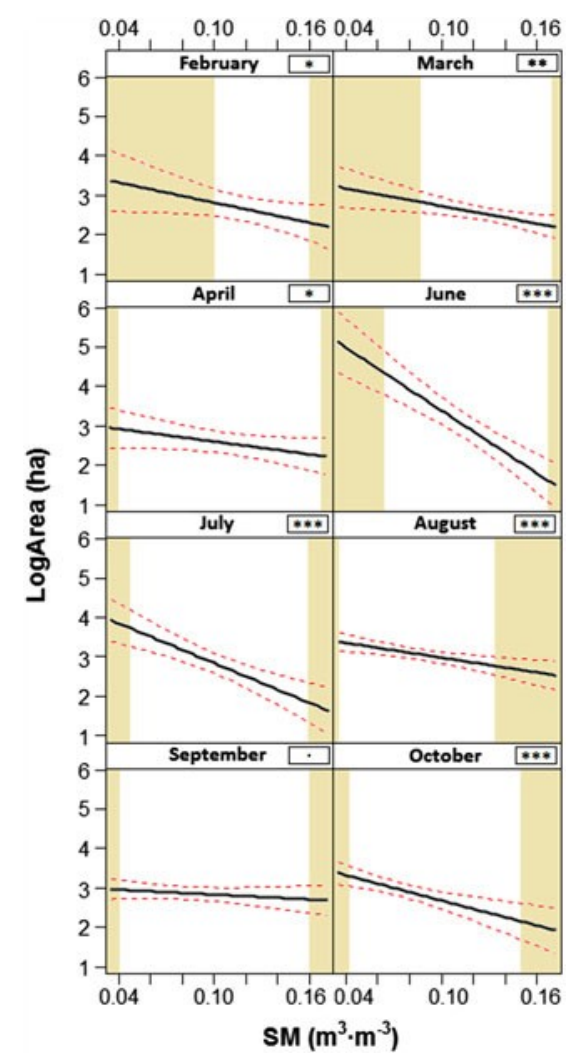

Fig. 8. Modeled effect of soil moisture on the potential extension of wildfires for each of the significant interactions between soil moisture and month. Black lines show the modeled effects and dashed lines show 95\% confidence intervals. Shaded rectangles show moisture values out of the range for each region, where effects are extrapolated. Top-right boxes show the significance of the effects for a given month, as $p<0.1$ (.), $p<0.05(*), p<0.01(* *)$ and $p<0.001$ (* $* *)$.

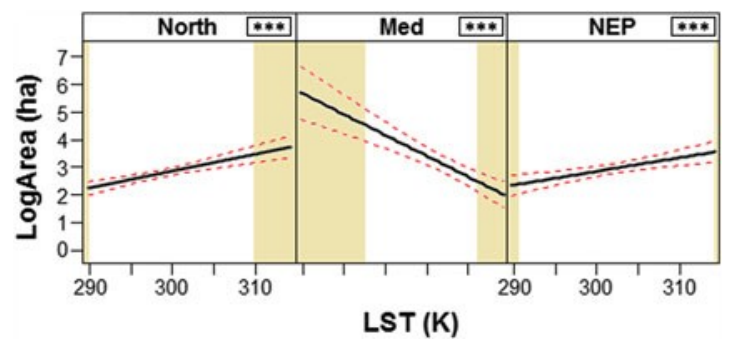

Fig. 9. Modeled effect of the surface temperature on the potential extension of wildfires for each of the significant interactions between surface temperature and regions: northern Iberian Peninsula (North), Mediterranean (Med) and northeastern Portugal (NEP). Black lines show the modeled effect and dashed lines show 95\% confidence intervals. Shaded rectangles show temperature values out of the range for each region, where effects are extrapolated. Top-right boxes show the significance of the effects for a given region, as $p<0.1(),. p<0.05(*), p<0.01(* *)$ and $p<0.001(* * *)$.

A relationship among soil moisture, land surface temperature and burned area was found considering the largest fires in each combination of moisture-temperature conditions. Not surprisingly, a considerable percentage of fires occurred under high temperatures and dry soils, but low soil moisture and high temperatures did not directly determine fire ignition or burned area (see Figs. 5 and 6). Indeed, wildfire ignition and spreading are strongly linked to a wide range of variables related to human, weather and biogeographical factors not considered in

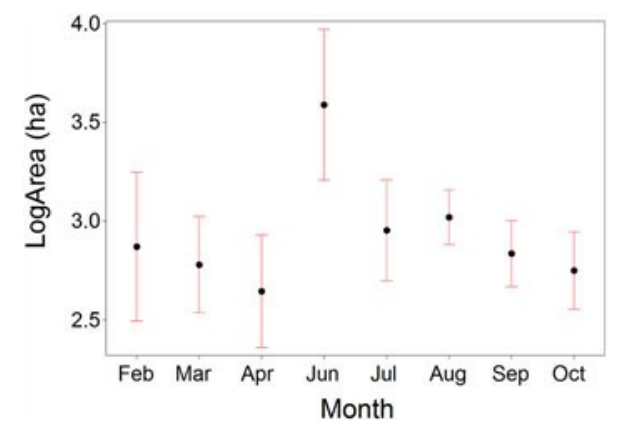

Fig. 10. Model coefficients showing the predicted logarithm of potential burned area for each of the studied months in the proposed model. Central black dots indicate the median. Whiskers account for \pm 1.58 IQR (Inter-Quartile Range).

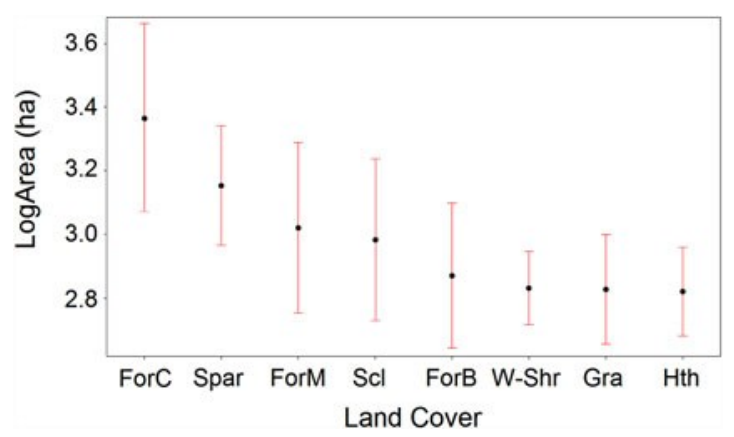

Fig. 11. Model coefficients showing the predicted logarithm of potential burned area for each of the studied land cover in the proposed model. Land cover acronyms represent: coniferous forests (ForC), sparse vegetation (Spar), mixed forest (ForM), sclerophyllous vegetation (Scl), broadleaved forests (ForB), wood-shrubland transitions (W-Shr), natural grasslands (Grass), and heathlands and moors (Hth). Central black dots indicate the median. Whiskers account for \pm 1.58 IQR (Inter-Quartile Range).

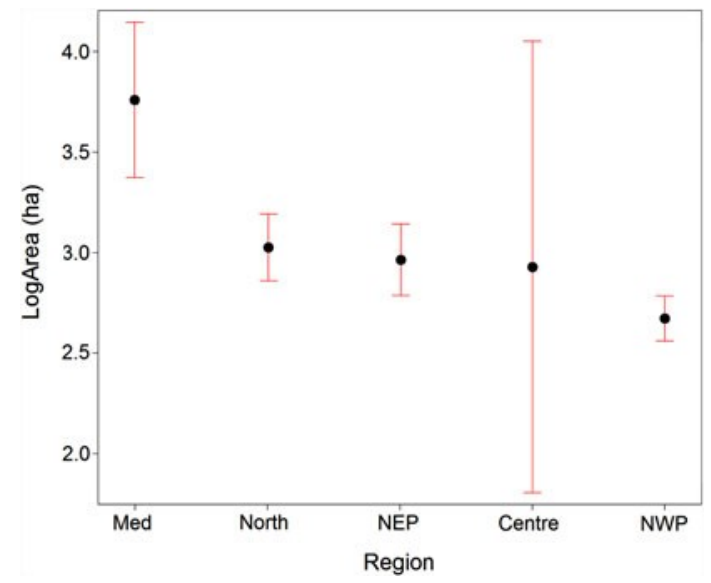

Fig. 12. Model coefficients showing the predicted logarithm of potential burned area for each of the studied region in the proposed model: Mediterranean (Med), northern Iberian Peninsula (North), northeastern Portugal (NEP), central Iberian Peninsula (Centre), and northwestern Portugal (NWP). Central black dots indicate the median. Whiskers account for \pm 1.58 IQR (Inter-Quartile Range).

the model (see [5] and [13]). Particularly, the contribution of wind is essential in most cases, and the inclusion of this variable in combination with moisture and temperature must be a next goal in this line research. However, note that in high fire risk situations, the final burned area may not be in agreement with 
the extent predicted by fire risk indices [44], as other factors such as fire extinction capacity are not considered.

The land cover which resulted more vulnerable to wildfire spread was coniferous forests (see Fig. 11). The fact that conifers are prone to fire propagation is also found in previous works, which also stress that broadleaved forests are less dangerous areas [8], coherently with the results here obtained. In contrast, unexpectedly, wildland fires burning in sparse vegetation covers reached important sizes (see Fig. 11). We suggest that, possibly, part of this lands might correspond to abandoned crops intermingled with other vegetation areas. In that sense, it is interesting to note that burned area in the Iberian Peninsula during the last decades (1961-2005) is increasing in non-forested areas and decreasing in forests [44]. Nevertheless, a more detailed analysis of this land cover type would be needed to understand this effect. Also, the median burned area in mixed forests and sclerophyllous vegetation was higher than in other land covers. Concerning to sclerophyllous vegetation, its increased propagation risk is probably due to the fact that xerophytic vegetation is more flammable than mesophyitic vegetation [44]. Finally, note that the described effects of land covers on fire extension can be related also to other factors affecting fire propagation. For instance, coniferous forests are partially located in areas where topography facilitates the rapid spread of fires, and limits the accessibility of fire extinction services. Topography also conditions the local vegetation distribution [13].

The region accounting with the largest forest fires was the Mediterranean (see Fig. 12), which recorded few (only a 5\%) but large wildfires in the study period. The region is characterized by dry soils and high temperatures. On the one hand, this limits the fuel availability and, consequently, the number of ignitions. On the other hand, after some years of low fire activity, a substantial amount of fuel is accumulated, facilitating the development of large fires in the driest summers (e.g., 2012, [8], [44], [45]). The effect of dry soils increasing burned area is more evident in the Mediterranean (see Fig. 7), coherently with the climate-fire link in the region.

The effect of temperature on fire spread was unexpected in the Mediterranean. Actually, the relationship between burned area and surface temperature was negative (see Fig. 9). This might be explained by 1) the strong influence of soil moisture on the predicted potential burned area in the Mediterranean, 2) the importance of other factors not considered in this study (e.g., wind and orography), and 3) the fact that the studied forest fires in the region occurred in hot conditions (>297 K; see Fig. 9). The latter point suggests that surface temperature could be a factor weakly conditioning the extent of large wildfires burning in the warmest soils. A similar conclusion could be drawn in the central Peninsula, where no relationship was found between burned area and temperature, and forest fires burned at temperatures higher than $306 \mathrm{~K}$. However, this is unclear as the sample for the central Spanish region is little $(n=6)$, and the lack of temperature effect was also observed in northeastern Portugal, where the range of temperatures prior to fire occurrence was wide (see Fig. 9).

In the northern Peninsula and the north of Portugal, which are the more humid regions, warm and dry soils increased the potential burned area (with the exception of northwestern Portugal, where only the moisture effect was significant). In these regions wet soils prevail. Consequently, fuel is largely available but its low flammability limits the spread of wildfires. Generally, large forest fires occur in humid regions when drought and/or heat events dry the available fuel [8]. This can explain the effect of dry soils and high temperatures increasing propagation risk in these regions. A similar effect was found in dry soils of the central Iberian Peninsula (see Figs. 7 and 9).

Finally, dry soils increased the potential extent of fires during most months, and especially in summer (see Fig. 8), possibly being a trigger factor at high temperatures. Also, summer months were the ones with higher burned area. However, the increased effect on June is probably due to a limited sample ( $n=7$; Fig. 10).

\section{B. Predicting Potential Burned Area as a Risk of Fire Propagation}

The model proposed in (2) explained an important part of the variance (68\%) of the potential burned area as a function of moisture-temperature conditions. The validation showed 83.3\% of agreement with a maximum error of 40.5 ha.

Soil moisture explained 33\% of the potential burned area variability. This result suggests that the use of remotely sensed soil moisture data could help anticipating forest fires extension in the Iberian Peninsula. Also, the near real time availability of the SMOS dataset in the region facilitates its application in early warning systems in the Iberian Peninsula. The applicability of land surface temperature in fire prevention services requires further investigation for the prospect use of forecasted and/or remotely sensed temperature data. Previous results suggested that combining forecasted surface temperature with remotely sensed soil moisture partially explains burned area [46]. Here, the effect of surface temperatures was only clear in some regions, and it should be a matter of future research especially in the Mediterranean region. Regarding land cover, region, and month, these variables are easy to obtain and apply.

A complementary model excluding the month of occurrence (see (3)) was needed for validation and future application in the months of January, May, November and December, which accounted with small samples. Similarly, a model excluding land cover was defined in (4) and it is applicable in agricultural areas. Both equations were validated and the results obtained were similar to those from the main model. Also, note that most studied fires burned in northwestern Iberian Peninsula (see Fig. 1). The use of a longer fire record would be necessary to neutralize these shifting and to extend the final model to central and Southern Portugal. Then, further research including a larger sample (more years of moisture, temperature and forest fires data) is needed in order to improve the model usefulness. Also, a longer dataset would help improving the reliability of the proposed model, which at the moment is limited by the availability of SMOS-derived data (5 years in this study).

Despite these limitations, the proposed methodology is the start point for future research in two important ways. Firstly, it will be needed to combine surface moisture-temperature data 
with wind information. Secondly, the proposed methodology sets the basis for future research that integrates soil moisturetemperature and wildfires to a common framework including wind and other weather-related variables, human-derived factors, orography and vegetation information.

At the moment, the implementation of the models is feasible. Results showed how the suggested methodology provides good approximation to the maximum expected fire spread. Its applicability will increase with its integration in more complex fire spread prediction tools.

\section{CONCLUSION}

Pre-fire conditions in the Iberian Peninsula were analyzed for the period 2010-2014 using SMOS-derived soil moisture and ERA-Interim land surface temperature data. Low surface temperatures and wet soils limited wildfires spread, while dry soils and high temperatures were linked to large burned areas. A linear regression between moisture-temperature conditions and maximum fire extent explained $43 \%$ of the potential burned area variability. The model equation was completed adding land cover, region and month of the fire outbreak, to the moisturetemperature conditions. Finally, 68\% of the model variance was explained. Validation showed $83.3 \%$ of agreement, with a maximum error of 40.5 ha. As expected, the Mediterranean was the region prone to suffer the largest wildfires. Coniferous forests were the land cover presenting a higher risk of fire spread. Results showed that dry soil conditions lead to large fires in most regions due to the importance of the fuel desiccation.

An operational implementation of the model needs to be adapted to observed or forecasted temperatures, in order to provide near real time information. First approximations suggested that this would be feasible. Complementary models to be used in particular months as well as in agriculture areas should be applicable without significantly increasing the error rate. However, future research is needed using a longer dataset in order to extend the methodology to central and Southern Portugal, and to strengthen the robustness of the proposed models.

The suggested methodology provides a good approximation to the potential fire extent for the case of the Iberian Peninsula, and the operational implementation of the model is feasible. Longer datasets as well as its integration within well-known fire risk indices (e.g., FFMC) would be needed to ensure its practical implementation.

\section{ACKNOWLEDGMENT}

Fires data were provided by the European Forest Fire Information System-EFFIS (http://effisjrc.ec.europa.eu) of the European Commission Joint Research Centre.

\section{REFERENCES}

[1] FAO, "Fire management-global assessment 2006," in A Thematic Study Prepared in the Framework of the Global Forest Resources Assessment 2005. Rome, Italy: Food and Agriculture Organization, 2007.

[2] D. M. Theobald and W. H. Romme, "Expansion of the US wildland-urban interface,” Landscape Urban Planing vol. 83, pp. 340-354, 2007.
[3] V. C. Radeloff, R. B. Hammer, S. I. Stewart, J. S. Fried, S. S. Holcomb, and J. F. McKeefry, "The wildland-urban interface in the United States," Ecol. Appl., vol. 15, no. 3, pp. 799-805, 2005.

[4] J. D. Cohen, "The wildland-urban interface fire problem: A consequence of the fire exclusion paradigm," Forest Hist. Today, vol. Fall 2008 pp. 20-26, 2008.

[5] M. Padilla and C. Vega-García, "On the comparative importance of fire danger rating indices and their integration with spatial and temporal variables for predicting daily human-caused fire occurrences in Spain,” Int. J. Wildland Fire, vol. 20, pp. 46-58, 2011.

[6] A. D. Syphard et al., "Predicting spatial patterns of fire on a southern California landscape,” Int. J. Wildland Fire, vol. 17, pp. 602-613, 2008.

[7] J. Martínez, C. Vega-García, and E. Chuvieco. "Human-caused wildfire risk rating for prevention planning in Spain,” J. Environ. Manage., vol. 90, pp. 1241-1252, 2009.

[8] F. Verdú, J. Salas, and C. Vega-García, “A multivariate analysis of biophysical factors and forest fires in Spain, 1991-2005,” Int. J. Wildland Fire, vol. 21, pp. 498-509, 2012.

[9] E. Chuvieco et al., "Development of a framework for fire risk assessment using remote sensing and geographic information systems,” Ecol. Model., vol. 221, no. 1, pp. 46-58, 2010.

[10] J. Salas and E. Chuvieco, "GIS applications for forest fires risk mapping," Wildfire. vol. 3, pp. 7-13, 1994.

[11] S. J. Pyne, P. L. Andrews, and R. D. Laven, Introduction to Wildland Fire”. NewYork, USA: Wiley, 1996

[12] A. Duane, M. Piqué, M. Castellnou, and L. Brotons, "Predictive modelling of fire occurrences from different fire spread patterns in Mediterranean landscapes,” Int. J. Wildland Fire, vol. 24, pp. 407-418, 2015.

[13] R. J. Whelan, The Ecology of Fire. Cambridge, U.K.: Cambridge Univ. Press, 1995

[14] B. G. Dickson, J. W. Prather, Y. Xu, H. M. Hampton, E.N. Aumack, and T.D. Sisk, "Mapping the probability of large fire occurrence in northern Arizona, USA,” Landscape Ecol., vol. 21, pp. 747-761, 2006.

[15] A. S. Ardakani, M. J. Valadan Zoej, A. Mohammadzadeh, and A. Mansourian, "Spatial and temporal analysis of fires detected by MODIS data in northern Iran from 2001 to 2008,” IEEE J. Sel. Topics Appl. Earth Observ. Remote Sens., vol. 4, no. 1, pp. 216-225, Mar. 2011.

[16] R.M. Trigo et al., "Atmospheric conditions associated with the exceptional fire season of 2003 in Portugal,” Int. J. Climatol., vol. 26, pp. 1741-1757, 2006.

[17] M. Oppenheimer, M. Campos, W. Warren, J. Birkmann, G. Luber, B. O’Neill, and K. Takahashi, “Emergent risks and key vulnerabilities,” in Climate Change 2014: Impacts, Adaptation, and Vulnerability. Working Group II Contribution to the IPCC 5th Assessment Report, T. F. Stocker, D. Qin, G.-K. Plattner, M. Tignor, S.K. Allen, J. Boschung, A. Nauels, Y. Xia, V. Bex, and P.M. Midgley, Eds., Cambridge, U.K.: Cambridge Univ. Press, 2014.

[18] J. H. Christensen, et al., Regional climate projections, in Climate Change 2007: The Physical Science Basis. Contribution of Working Group I to the Fourth Assessment Report of the Intergovernmental Panel on Climate Change, S. Solomon, D. Qin, M. Manning, Z. Chen, M. Marquis, K.B. Averyt, M. Tignor, and H.L. Miller, Eds. Cambridge, U.K.: Cambridge Univ. Press, 2007.

[19] E. Chuvieco, et al., "Combining NDVI and surface temperature for the estimation of live fuel moisture content in forest fire danger rating," Remote Sens. Environ., vol. 92, pp. 322-331, 2004.

[20] E. M. Fischer, S. I. Seneviratne, P. L. Vidale, D. Lüthi, and C. Schär, "Soil moisture-atmosphere interactions during the 2003 European summer heat wave,” J. Climate, vol. 20, no. 20, pp. 5081-5099, 2007.

[21] Deeming, J. E., Burgan, R. E., and Cohen, J. D., “The National fire-danger rating system - 1978,” USDA Forest Service, Rocky Mountain Forest and Range Experiment Station, Odgen, Utah, Gen. Tech. Rep. INT-39, 1977.

[22] L. S. Bradshaw, J. E. Deeming, R. E. Burgan, and J. D. Cohen, compilers, "The 1978 national fire-danger rating system: Technical documentation," U.S. Department of Agriculture, Forest Service, Intermountain Forest and Range Experiment Station, Ogden, UT, Gen. Tech. Rep. INT-169, 1984.

[23] Y. H. Kerr, et al., "The SMOS Mission: New tool for monitoring key elements of the global water cycle,” Proc. IEEE, vol. 98, no. 5, pp. 666687, May 2010.

[24] D. Entekhabi, et al., "The soil moisture active passive (SMAP) mission," Proc. IEEE, vol. 98, no. 5, pp. 704-716, May 2010.

[25] A. Bartsch, H. Balzter, and C. George, "The influence of regional surface soil moisture anomalies on forest fires in Siberia observed from satellites," Environ. Res. Lett., vol. 4, 2009, Art. no. 045021. doi: 10.1088/17489326/4/4/045021. 
[26] M. Forkel, K. Thonicke, C. Beer, W. Cramer, S. Bartalev, and C. Schmullus, "Extreme fire events are related to previous-year surface moisture conditions in permafrost-underlain larch forests of Siberia,” Environ. Res. Lett., vol. 7, 2012, Art. no. 044021.

[27] S. Sánchez-Ruiz, M. Piles, N. Sánchez, J. Martínez-Fernández, M. Vall-llossera, and A. Camps, "Combining SMOS with visible and near/shortwave/thermal infrared satellite data for high resolution soil moisture estimates,” J. Hidrol., vol. 516, pp. 273-283, 2014.

[28] M. Piles, et al., "A downscaling approach for SMOS land observations: Evaluation of high resolution soil moisture maps over the Iberian Peninsula,” IEEE J. Sel. Topics Appl. Earth Observ. Remote Sens., vol. 7, no. 9, pp. 3845-3857, Sep. 2014.

[29] Barcelona Expert Centre, "CP34-BEC. BEC data distribution and visualization center,” 2015. [Online]. Available: http://cp34-bec.cmima.csic.es. Last accessed: 21st Jun. 2015.

[30] D. Chaparro, M. Vall-llossera, M. Piles, A. Camps, and C. Rüdiger, "Low soil moisture and high temperatures as indicators for forest fire occurrence and extent across the Iberian Peninsula," in Proc. IEEE Int. Geosci. Remote Sens. Symp., 2015, pp. 3325-3328.

[31] European Centre for Medium-Range Weather Forecasts, "ERAInterim Project,” 2015. [Online]. Available: http://www.ecmwf.int/en/ research/climate-reanalysis/era-interim. Last accessed: 12th September 2015.

[32] European Environment Agency, “Corine Land Cover Map,” 2006.

[33] J. M. Paes do Amaral, “Zonas fitogeográficas predominantes,” Ministerio do Ambiente e do Ordenamento do Território, Direcção-Geral do Ambiente, Lisboa, Portugal, 2000.

[34] European Comission, "Forest Fires in Europe 2009," Office for Official Publications of the European Communities, Luxembourg, Europe, EUR 24502 EN, 2010.

[35] M. G. Pereira, R. M. Trigo, C. C. da Camara, J. M. C. Pereira, and S. M. Leite, "Synoptic patterns associated with large summer forest fires in Portugal,” Agricultural Forest Meteorol., vol. 129, pp. 11-25, 2005.

[36] J. San-Miguel-Ayanz, J. M. Moreno, and A. Camia, "Analysis of large fires in European Mediterranean landscapes: Lessons learned and perspectives,” Forest Ecol. Manage., vol. 294, pp. 11-22, 2013.

[37] Agencia Estatal de Meteorología (AEMET). "Resumen anual climatológico 2012,” 2012. [Online]. Available: http://www.aemet.es/es /serviciosclimaticos/vigilancia_clima/resumenes.

[38] J. G. Pausas, "Changes in fire and climate in the eastern Iberian Peninsula (Mediterranean basin)”, Climatic Change., vol. 63, pp. 337-350, 2004.

[39] P. de Zea Bermúdez, J. Mendes, J. M. C. Pereira, K. F. Turkman, and M. J. P. Vasconcelos, "Spatial and temporal extremes of wildfire sizes in Portugal (1984-2004),” Int. J. Wildland Fire., vol. 18, pp. 983-991, 2009.

[40] C. Aguiar, S. Mesquita, and J. Honrado, “Introdução à carta biogeográfica de Portugal (Costa et al. 1998)," in Costa et al., Atlas das Aves Nidificantes em Portugal. Lisboa: Instituto da Conservação da Natureza e da Biodiversidade, Assírio \& Alvim, pp. 47-50, 2008.

[41] J. C. Costa, C. Aguiar, J. Capelo, M. Lousã, and C. Neto, "Biogeografia de Portugal Continental,” Quercetea, vol. 1, pp. 5-56, 1998.

[42] M. S. Moran, T. R. Clarke, Y. Inoue, and A. Vidal, "Estimating crop water deficit using the relation between surface-air temperature and spectral vegetation index," Remote Sens. Environ., vol. 49, pp. 246-263, 1994.

[43] I. Sandholt, K. Rasmussen, and J. Andersen, “A simple interpretation of the surface temperature/vegetation index space for assessment of surface moisture status,” Remote Sens. Environ., vol. 79, pp. 213-224, 2002.

[44] J. M. Moreno et al., "Impactos sobre los riesgos naturales de origen climático. Riesgo de incendios forestales,” in “Evaluación Preliminar de los Impactos en España por Efecto del Cambio Climático. Proyecto ECCE - Informe final” Coord. J.M. Moreno Ed., Ministerio de Medio Ambiente, 2005.

[45] Agencia Estatal de Meteorología, Ministerio de Agricultura, Alimentación y Medio Ambiente, “Resumen annual climatológico,” 2012.

[46] D. Chaparro, M. Vall-llossera, M. Piles, A. Camps, and C. Rüdiger, "Low soil moisture and high temperatures as indicators for forest fires occurrence and extent across the Iberian Peninsula.” in presented at the 2nd SMOS Sci. Conf., Madrid, Spain, pp. 25-29, May 2015.

[47] J. Fox, "Effect displays in R for generalized linear models,” J. Stat. Softw., vol. 8, no. 15, pp. 1-27, 2003. 